\title{
RESEARCH
}

\section{Prevalence of Chronic Gingivitis Among 16 Years Old Public High School Students in Khartoum}

\author{
Abubakr Omar Mohamed Abdelsalam*1,2, Ibrahim Ahmed Ghandour ${ }^{2}$ \\ ${ }^{1}$ Department of Periodontology, College of Dentistry, Misurata Universirty, Misurata, Libya \\ ${ }^{2}$ Department of Periodontology, Faculty of Dentistry, Universirty Khartoum, Khartoum, Sudan
}

Date of Submission : March 04, 2018

Received in Revised Form : March 24, 2018

Date of Acceptance : April 14, 2018

Date of Publishing : July 30, 2018

\section{ABSTRACT}

Background: This study was designed to measure the prevalence of chronic gingivitis among 16- year-old public high school students in Khartoum State.

Methods: A total of 385 high school students of 16 years of age, from public schools in different geographical locations representing different socioeconomic classes in Khartoum were randomly selected and examined. The variables of the present study had been collected by one examiner using a direct interview questionnaire and all the present teeth were examined at four sites (Mesiobuccal, distobuccal, mesiolingual, distolingual) for the presence of plaque, using the Plaque Index (Loe and Sillness) and Gingival Index (Sillness and Loe).

Results: Prevalence of gingivitis was $96.9 \%$, of which $68.6 \%$ were of mild form (majority), $27.5 \%$ of moderate condition and only $0.8 \%$ was of severe grade. The most common form of gingivitis was the generalized form that accounted for $94.5 \%$. The relationship between oral hygiene and degree of gingivitis was assessed after collecting data on study area, gender, socio-economic status, toothbrushing tool used, frequency of brushing per day, direction of tooth-brushing and regularity of dental visits. The adjusted relationship was still significant at the $99 \%$ confidence level (p-value 0.000 ), with a correlation coefficient of 0.704 .

Conclusions: The study showed significantly higher prevalence of chronic gingivitis among 16-year-old public high school students in Khartoum State. The degree of gingivitis showed statistical significance when correlated with oral hygiene status, socioeconomic status, frequency and horizontal direction of tooth brushing, while it showed insignificance when correlated with gender.

Keywords: Gingivitis, Socio-economic status, hygiene status, School students.

*Corresponding Author: Abubakr Omar Mohamed Abdelsalam, Department of Periodontology, College of Dentistry, Misurata Universirty,Misurata,Libya,Email: aseelwazeer@ gmail.com

\section{INTRODUCTION}

Oral hygiene was practiced by the Sumerians some 3000 years BC, who elaborately decorated golden tooth picks, suggesting an interest in cleanliness of the mouth. The gingiva is the part of the oral masticatory mucosa that covers the 
alveolar process of the jaw and surrounds the neck of the teeth. It consists of an outer epithelial layer, and an underlying connective tissue layer called the lamina propria. ${ }^{1,2}$ The gingiva is anatomically divided in to marginal, attached and interdental areas. Gingivitis is inflammation of the gingiva in which the junctional epithelium remains attached to the tooth at its original level. ${ }^{3}$ This definition implies that gingivitis doesn't exist if the tooth has periodontitis. The primary cause of gingival diseases is bacteria; other causes may be viral, fungal, traumatic or foreign body reaction. Gingivitis that is associated with dental plaque formation is the most common form of gingival disease. ${ }^{4}$ All age groups can be affected with chronic gingivitis, but it is more common among adults. ${ }^{5}$ Clinical features of gingivitis include: redness, sponginess of the gingiva, bleeding on provocation, and change in contour, presence of calculus or plaque with no radiographic evidence of crestal bone loss. ${ }^{6}$ Epidemiological studies indicated that more than $82 \%$ of U.S. adolescents have overt gingivitis, and signs of gingival bleeding. ${ }^{7}$ In Sudan, a study was done to investigate the oral hygiene practice, the prevalence of dental plaque, gingivitis and calculus among 12-year-old Sudanese schoolchildren in Khartoum State, and to correlate the above to gender and educational level of parents. The results showed a high correlation between oral hygiene practice of the students and both parents' education. ${ }^{8}$ Prevalence of gingivitis in primary schools in Tanzania ranged from 55\%99\%. ${ }^{9}$ The importance of studying the prevalence of chronic gingivitis is that despite it is a reversible disease, but if not treated properly it may progress to chronic periodontitis, with the resultant sequelae of chronic periodontitis including: attachment loss; alveolar bone loss, mobility of teeth and eventually loss of teeth. The aim of the present study was designed to identify the prevalence of chronic gingivitis among 16 years old public high school students in Khartoum, Sudan to be used as an indication for the prevalence in the general public.

\section{MATERIALS AND METHODS}

\section{Study design}

This descriptive cross- sectional study included public high school students in Khartoum state of 16 years of age. Only those willing were included in the study. Those with full or partial dentition (at least 8 teeth excluding 3rd molar), those with systemic disease and those who smoked and were unwilling to participate in the study, edentulous patients and finally those with a history of recent periodontal therapy were excluded from the study.

\section{Examination}

The clinical examinations was performed by one examiner (A.O.A). All present teeth were examined at four sites (mesiobuccal, distobuccal, mesiolingual, distolingual) for the presence of plaque, using the Plaque Index (Loe and Sillness) and Gingival Index (Sillness and Loe) for assessment of bleeding. ${ }^{10}$ Cross infection control: Face mask and a Pair of examination gloves were used for the examination of each subject and discarded after use.

\section{Material and Tools for data collection}

Interview questionnaires: consisting of demographic data, socio economic status, oral hygiene behaviour and general health of the participant. Dental examination set: Plain mouth mirror and WHO graduated periodontal probe were used to assess the different parameters. Indices used were the Gingival Index (GI) and the Plaque Index (PI).

\section{Sample size}

The sample size was estimated to be $385(16$ years old) high school students. It was calculated using win episcope version 2.0 given that the confidence level is $95 \%$, level of precision $5 \%$, expected prevalence $50 \%$ and population size of 106,602 students aged 16 years distributed in public high schools all over Khartoum State.

\section{Sample technique}

Stratified multi-stage sampling was used. The first stage was selecting the schools from all seven localities of Khartoum State. The stratification variable is the number of students.

\section{STATISTICAL ANALYSIS}

Data were analysed using SPSS (Statistical Package for Social Sciences) version ${ }^{11}$. Descriptive analysis was performed to determine the prevalence of gingivitis among the studied sample and compared across age, gender and 
different localities of Khartoum state. For all statistical tests, two-sided type I error probability $=0.05$ was considered as the level of significance.

\section{RESULTS}

A total of 385 high school students were included in the study from the three localities of Khartoum, Sudan as follows: The largest number was from KhartoumNorth 150students(39\%), 131(34\%)from Omdurman and 104 (27\%) from Khartoum (Table 1). There was no significant difference regarding the proportion of males and females, since the number of female students was 195(50.6\%), whereas the number of male students was $190(49.40 \%)$ (Table2). The majority of students use tooth brush for mouth cleaning 369 (95.8\%), miswak users were only14 (3.6\%), and only two students $(0.5 \%)$ didn't brush their teeth (Table 3). The highest frequency of brushing was once per day done by 318 (95.8\%) students (Table 4).The favourite direction of tooth brushing technique used by most of the students was horizontal 312(81\%), vertical 35(9.1\%), both vertical and horizontal 36(9.4\%) (Table5). 376 students $(97.7 \%)$ did not visit the dentist regularly; only 9 students $(2.3 \%)$ did (Table 6$)$. The majority of students $379(98.4 \%)$ had good oral hygiene status; whereas only 6 students $(1.6 \%)$ had fair oral hygiene status (Table 7). The total prevalence of gingivitis was $96.9 \%$, of which $68.6 \%$ were of mild form (majority), $27.5 \%$ of moderate condition and only $0.8 \%$ were of the severe type (Table 8 ). The most common form of gingivitis was the generalized form that accounts for 94.5\% (Table 9). There was no statistically significant difference regarding the distribution of sample according to gender and study area. (P-value $=0.547)$ (Table 10). There was no statistically significant difference regarding the distribution of sample according to socio-economic status and study area. (P-value $=0.192)$ (Table 11).There was no statistically significant difference regarding the distribution of sample according to tooth-brushing tool used and study area (Table 12).There was a statistically significant difference regarding the distribution of sample according to direction of tooth-brushing and study area, the horizontal was the most in use by students $81.0 \%$.(P-value $=0.007)$ (Table 13). As the oral hygiene of the patients gets worse by 1 degree, the probability of gingivitis occurrence increases by 0.745 degree. This relationship was statistically significant at the $99 \%$ confidence level. The relationship between oral hygiene and degree of gingivitis was assessed after controlling for study area, gender, socio-economic status, tooth-brushing tool used, frequency of brushing per day, direction of tooth-brushing and regularity of dental visits. The adjusted relationship was still statistically significant at the $99 \%$ confidence level (p-value 0.000 ), with correlation coefficient of 0.704 .

Table 1. The Distribution of sample according to Study Area

\begin{tabular}{|c|c|}
\hline Area & No(\%) \\
\hline Khartoum & $150(39.0)$ \\
\hline KhartoumNorth & $104(27.0)$ \\
\hline Omdurman & $131(34.0)$ \\
\hline Total & $385(100.0)$ \\
\hline
\end{tabular}

Table 2. The Distribution of sample according to gender

\begin{tabular}{|l|l|}
\hline Gender & No(\%) \\
\hline Male & $190(49.4)$ \\
& $195(50.6)$ \\
Female Total & $385(100.0)$ \\
\hline
\end{tabular}

$\mathrm{P}$ value $=0.547$

Table 3. The Distribution of sample according to Socio-economic Status

\begin{tabular}{|c|c|}
\hline SES & No $(\%)$ \\
\hline High & $16(4.2)$ \\
\hline Moderate & $204(53.0)$ \\
\hline Low & $165(42.9)$ \\
\hline Total & $385(100.0)$ \\
\hline
\end{tabular}

$\mathrm{P}$ Value $=0.192$

Table 4. The distribution of sample according to tooth brushing tool used.

\begin{tabular}{|c|c|}
\hline Tooth brushing tool & No(\%) \\
\hline Toothbrush & $369(95.8)$ \\
\hline Miswak & $14(3.6)$ \\
\hline None & $2(0.5)$ \\
\hline Total & $385(100.0)$ \\
\hline
\end{tabular}

$\mathrm{P}$ Value $=0.727$

Table 5. The distribution of sample according to Frequency of tooth brushing per day

\begin{tabular}{|c|c|}
\hline Frequency & No $(\%)$ \\
\hline Once & $318(82.6)$ \\
\hline Twice & $60(15.6)$ \\
\hline More than Twice & $5(1.3)$ \\
\hline Not Applicable (Don't brush) & $2(0.5)$ \\
\hline Total & $385(100.0)$ \\
\hline
\end{tabular}

$\mathrm{P}$ Value $=0.148$ 
Table 6. The distribution of sample according to direction of tooth-brushing

\begin{tabular}{|l|c|}
\hline Direction & No $(\%)$ \\
\hline Horizontal & $312(81.0)$ \\
\hline Vertical & $35(9.1)$ \\
\hline Both Horizontal \&Vertical & $36(9.4)$ \\
\hline No brushing & $2(0.5)$ \\
\hline Total & $385(100.0)$ \\
\hline
\end{tabular}

$\mathrm{P}$ Value $=0.007$

Table 7. The distribution of sample according to regularity of dental visits

\begin{tabular}{|l|c|}
\hline Visit to dentist & No (\%) \\
\hline Yes & $9(2.3)$ \\
\hline No & $376(97.7)$ \\
\hline Total & $385(100.0)$ \\
\hline
\end{tabular}

$\mathrm{P}$ Value $=0.191$

Table 8. The distribution of sample according to oral hygiene status (OHS).

\begin{tabular}{|c|c|}
\hline OHS & No (\%) \\
\hline Good & $379(98.4)$ \\
\hline Fair & $6(1.6)$ \\
\hline Total & $385(100.0)$ \\
\hline
\end{tabular}

$\mathrm{P}$ Value $=0.16$

Table 9. The distribution of sample according to degree of gingivitis

\begin{tabular}{|l|c|}
\hline Degree of gingivitis & No (\%) \\
\hline Healthy & $12(3.1)$ \\
\hline Mild & $264(68.6)$ \\
\hline Moderate & $106(27.5)$ \\
\hline Severe & $3(0.8)$ \\
\hline Total & $385(100.0)$ \\
\hline
\end{tabular}

Table 10. Periodontal Disease Status

\begin{tabular}{|l|c|}
\hline Area of gingival inflammation & No (\%) \\
\hline Healthy & $12(3.1)$ \\
\hline Localized Marginal & $8(2.1)$ \\
\hline Localized Papillary & $1(0.3)$ \\
\hline Generalized & $364(94.5)$ \\
\hline Total & $385(100.0)$ \\
\hline
\end{tabular}

Table 11.Mean standard deviation and range of Periodontal Indices for the Sample

\begin{tabular}{|l|c|c|}
\hline Description & Mean \pm SD & Range \\
\hline Calculus Index & $0.06 \pm 0.15$ & $0.00-1.19$ \\
\hline Plaque Index & $1.07 \pm 0.32$ & $0.11-2.29$ \\
\hline OHI-S & $0.57 \pm 0.22$ & $0.06-1.71$ \\
\hline Gingival Index & $1.07 \pm 0.38$ & $0.00-2.32$ \\
\hline
\end{tabular}

Table 12. Comparison of Gender distribution according to Study area.

\begin{tabular}{|c|c|c|c|c|}
\hline \multirow[b]{2}{*}{ Description } & \multicolumn{3}{|c|}{ Study Area } & \multirow[b]{2}{*}{ Total No(\%) } \\
\hline & $\begin{array}{c}\text { Khartoum } \\
\text { No(\%) }\end{array}$ & $\begin{array}{c}\text { Khartoum } \\
\text { North } \\
\text { No(\%) }\end{array}$ & $\begin{array}{c}\text { Omdurman } \\
\mathrm{No}(\%)\end{array} \mid$ & \\
\hline Male & $55(52.9)$ & $75(50.0)$ & $60(45.8)$ & $190(49.4)$ \\
\hline Female & $49(47.1)$ & $75(50.0)$ & $71(54.2)$ & $195(50.6)$ \\
\hline Total & $104(100.0)$ & $150(100.0)$ & $131(100.0)$ & $385(100.0)$ \\
\hline
\end{tabular}

Table 13. Comparison of Socio-economic status according to study area.

\begin{tabular}{|c|c|c|c|c|}
\hline & \multicolumn{3}{|c|}{ Study area Khartoum } & Total \\
\hline 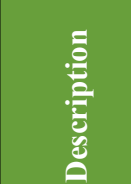 & 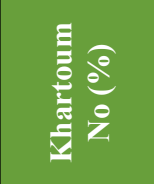 & 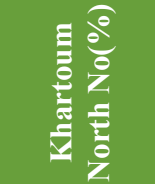 & 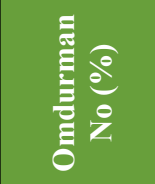 & $\underset{e}{\hat{e}}$ \\
\hline High & $7(6.7)$ & $8(5.3)$ & $1(0.8)$ & $16(4.2)$ \\
\hline Moderate & $53(51.0)$ & $78(52.0)$ & $73(55.7)$ & $204(53.0)$ \\
\hline Low & $44(42.3)$ & $64(42.7)$ & $57(43.5)$ & $165(42.9)$ \\
\hline Total & $104(100.0)$ & $150(100.0)$ & $131(100.0)$ & $385(100.0)$ \\
\hline
\end{tabular}

\section{DISCUSSION}

No study was previously done in Khartoum state concerning the prevalence of chronic gingivitis among 16-year-old public high school students. This study revealed that the prevalence of chronic gingivitis among 16-year-old public high school students was $96.9 \%$ of which $68.6 \%$ were of mild form (majority), $27.5 \%$ of moderate form and only $0.85 \%$ were severe form. The result agrees with those of a study done by Sayed Jalal in Iran in 2007 who showed that $(95.8 \%)$ of students examined were affected by gingivitis. ${ }^{11}$ The strong agreement of the results of the present study with that in Iran may be due to similarity in culture and even the sample size (385 vs. 442 students). Previously similar study was performed in Brazil by MariaAugusta in 2009 which revealed that the prevalence of chronic gingivitis among high school students was $94.1 \%$, which is also in agreement with the present study and that might be due to using of the same methodology: Interview questionnaires and clinical examination by using Plaque Index (Loe and Sillness) and gingival index (Sillness and Loe) and age group(15-19 years) despite the big difference in sample size of the study in Brazil (889 students). ${ }^{12}$ Jebun Nessain in 2004 studied the prevalence of gingivitis in Bangladesh. ${ }^{13}$ This study also showed high prevalence of gingivitis (89\%). Though the results of this Bangladeshi study and my study were similar, the age range of participants was 10-65 years (majority were students) with a small sample size of 117.

Regarding the relationship of the degree of gingivitis with gender, it was statistically not significant in this present study; males accounted for $49.4 \%$ while females were $50.6 \%$ of the total sample. This study showed that oral hygiene status directly and strongly influences gingival health. The present study showed that the degree of gingivitis versus 
horizontal direction of brushing was statistically significant. $81 \%$ of the total studied population brush horizontally had the pathology.

There were some limitations of present study. High school students in Khartoum state who were 16 years of age and included for this study may not necessarily represent the same age group on the national level in the country as a whole. Moreover the selected students for clinical examination brushed their teeth prior to clinical examination. Hence, another study that would include other age groups and patients from varied social strata is needed before we make conclusions on the gingival disease parameters for the Sudanese society.

\section{CONCLUSION}

Data showed significantly higher prevalence of chronic gingivitis among 16-year-old public high school students in Khartoum state. Oral hygiene status directly and strongly influences gingival health and so does the socio-economic status of the patients including their parents' level of education. Moreover, there was a positive correlation between the degree of gingivitis and frequency of tooth brushing with most of the students brushing only once a day. Similarly, the degree of gingivitis versus horizontal direction of brushing was statistically significant.

\section{Conflict of interest}

It is assured that there is no conflict of interest of any kind in any spheres.

\section{Acknowledgement}

Authors are jointly thankful from the bottom of their hearts to Honorable President, Misurata University, Misurata, Libya, for providing necessary facilities in university premises for this research.

\section{REFERENCES}

1. Schroeder HE. Gingiva. In: Oksche A, VollrathL. Theperiodontium handbook of microscopic anatomy,vol. 5. Berlin:Springer-Verlag; 1986.

2. Ainamo J, Loe H. Anatomical characteristics of gingiva: A clinical and microscopic study of the free and attached gingiva. $\mathrm{J}$ Periodontal. 1966; 37:5.
3. Genco RJ, Goldman HM, Cohen DW: Contemporary periodontics. St. Louis, Mosby. 1990; 113-18.

4. Aldred MJ, Bartold PM: Genetic disorders of the gingivae and periodontium. Periodontal. 1998; 18:7.

5. Alabander JM, Rams TE. Global Epidemiology of periodontal disease: An Overview. Periodontal. 2000; 29: 7, 2002.

6. American Academy of Periodontology: Parameters on plaque induced gingivitis. $\mathbf{J}$ Periodontol. 2000; 71: 851.

7. Albandar JM, Brown LJ, Brunelle JA. Gingival state and dental calculus in earlyonset periodontitis. J Periodontol. 1996; 67:953.

8. Farah HH, Ghandour IA. Periodontal health status of 12 years old Sudanese School children and education all level of parents in Khartoum Province. Odontostomatol Trop. 2009; 32(127): 25-33.

9. Kikwilu EN. Prevalence of gingivitis in primary schools in Tanzania. East African J. 2001; 78:3.

10. Loe $\mathrm{H}$. The gingival index, the plaque index and the retention in decsystem. J Periodontol. 1967; (9):1645-51.

11. Pourhashemi SJ, Motlagh MG, Jahed GR. Prevalence and Intensity of Gingivitis among 6-10 years old elementary school children in Tehran, Iran. J Med Sci. 2007; 7(5): 830-834.

12. Bessa MA, Lopes MC, Rebelo JM, Pereira RC. Dental caries and gingivitis among 15 to 19 year-old students in Manaus, AM, Brazil. Braz Oral. 2009; 23(3): 248-54.

13. Nessa J, Choudhury SR. Gingivitis: A Common preventable oral health problem. The J Teachers Ass, RMC, Rajshahi, TAJ June 2004; 17 (1): 11-15.

14. Deepak PA, Shyagali TR, Malikarjun K. Study of oral hygiene status and prevalence of gingival disease in 10-12 school children in Maharashtra, India. JIOH. 2010; 2(3): 21-6. 